\title{
The Metabolism of an Exogenous Lipid Source during Septic Shock in the Puppy
}

\author{
Arnold G. Coran, MD., ${ }^{*}$ Robert A. Drongowski, M.S.,† Grace S. Lee, B.S., \\ Michael D. Klein, M.D.,§ AND John R. Wesley, M.D. ॥ \\ From the Section of Pediatric Surgery, Mott Children's Hospital and University of Michigan Medical School, Ann Arbor, Michigan
}

\begin{abstract}
Septic shock induces physiologic and hemodynamic responses that may alter the host's ability to metabolize an exogenous source of lipids. The present study examined the metabolic changes occuring during septic shock in the young animal receiving an intravenous fat emulsion. Five 8-wk-old male Beagle puppies were studied. Each animal served as his own control twice, during which time ${ }^{14} \mathrm{C}$-palmitic acid alone or with a $10 \%$ fat emulsion (Liposyn) was administered. Septic shock (cardiac output less than $50 \%$ of control) was induced with an intravenous bolus of live Escherichia coli. During shock the puppies received intravenous ${ }^{14} \mathrm{C}$-palmitic acid and Liposyn. The mean respiratory quotient for the shock dogs $(0.96 \pm 0.01)$ was significantly $(p<0.05)$ higher than that of the controls $(0.83 \pm 0.06)$. The amount of expired ${ }^{14} \mathrm{CO}_{2}$ was $25.0 \pm 15.9 \%$ for the shock animals, $53.9 \pm 28.1 \%$ for the Liposyn controls, and $75.7 \pm 30.5 \%$ for the controls receiving only ${ }^{14} \mathrm{C}$-palmitic acid (these differences are all significant, $p<0.05$ ). After the
\end{abstract}

onset of shock, serum triglyceride levels peaked within $2 \mathrm{~min}$ at $851 \pm 540 \mathrm{mg} / 100 \mathrm{ml}$ and remained elevated at $333 \pm 213$ $\mathrm{mg} / 100 \mathrm{ml}$. Triglyceride levels in the Liposyn control animals returned to baseline values $(54 \pm 13 \mathrm{mg} / 100 \mathrm{ml})$ at the end of the 4 -hr experimental period. Free fatty acids in the shock dogs reached a maximal level of $1.44 \pm 0.09 \mathrm{mEq} / \mathrm{liter}$ at $1 \mathrm{hr}$ and remained at this elevated value for a significantly longer period of time than in the Liposyn control puppies. Glycerol value followed a similar pattern and cholesterol remain unchanged. Plasma insulin in the shock animals steadily rose to a peak of $826 \pm 358 \mu \mathrm{U} / \mathrm{ml}$ at the end of the experimental period; control animals showed no plasma insulin changes. The results of this study suggest that exogenous lipids administered during septic shock may not be metabolized as well as during the nonshock state. (Journal of Parenteral and Enteral Nutrition 8:652-656. 1984)

This study was undertaken to determine the effects of severe Escherichia coli bacteremic shock on lipid metabolism in puppies administered an intravenous fat emulsion.

\section{MATERIALS AND METHODS} ria. ${ }^{1-9}$ There are conflicting reports concerning the ability of animals and humans to utilize intravenous fats as an energy substrate during sepsis. Wannemacher et $\mathrm{al}^{10}$ studied patients and monkeys with pneumoccocal sepsis and reported a protein-sparing effect associated with the infusion of a lipid emulsion. Similarly, Nordenstrom et $\mathrm{al}^{11}$ have shown that intravenously administered fat emulsions are cleared from plasma and oxidized at accelerated rates in patients with trauma or infection compared with normal subjects. In contrast, Long et $\mathrm{al}^{12}$ reported minimal protein-sparing from fat emulsions in patients with severe burns.

Received for publication, January $30,1984$.

Accepted for publication, June 1, 1984

Reprint requests to: Arnold G. Coran, M.D., Head, Pediatric Surgery, Mott Children's Hospital F-7516, Box 66, Ann Arbor, MI 48109.

* Professor of Surgery and Head of the Section of Pediatric Surgery, University of Michigan Medical School, Surgeon-in-Chief, Mott Children's Hospital.

+ Research Associate. Pediatric Surgery Research Laboratories, Mott Children's Hospital.

† Medical Student. Eniversity of Michigan Medical School.

$\$$ Assistant Professor of Surgery. Section of Pediatric Surgery, University of Michigan Medical School.

II Associate Professor of Surgery, Section of Pediatric Surgery, University of Michigan Medical School.
Five 8-wk-old, colony-bred puppies were used in this study. Two control studies and one experimental study were established for each puppy, with a 1 -wk recovery period between experiments. All dogs were anesthetized with rompum (Bayvet, Shawnee, $\mathrm{KS}$ ), $2.5 \mathrm{mg} / \mathrm{kg} \mathrm{sc}$, and pentobarbitol, $25 \mathrm{mg} / \mathrm{kg}$ iv. Food was withheld for $8 \mathrm{hr}$ prior to each experiment but water was allowed ad libitum.

One femoral vein was cannulated for lipid administra tion and blood sampling. The other femoral vein was catheterized for measuring cardiac output with a pediatric, balloon-tipped thermodilution catheter passed into the pulmonary artery. The femoral artery was catheterized for monitoring systemic blood pressure.

A 1-hr equilibration period was established for all three animal groups. After this period, each of the five puppies received $50 \mu \mathrm{Ci}$ of ${ }^{14} \mathrm{C}$-palmitic acid iv (group A). Two days later, the same animals received the same dose of ${ }^{14} \mathrm{C}$-palmitic acid plus a fat emulsion (Liposyn $10 \%$, Abbott Laboratories, North Chicago, IL) at $0.5 \mathrm{~g}$ of fat/ $\mathrm{kg}$ iv (group B). After a 2-day rest, the five puppies were given an iv bolus of liver $E$. coli $(10 \mathrm{ml} / \mathrm{kg}$ of 109 colonies $E$. coli $/ \mathrm{ml}$, an $\mathrm{LD}_{100}$ dose) to induce septic shock (cardiac output $50 \%$ or less than baseline values). Ten minutes 
after septic shock was established, the animals were given the same doses of both ${ }^{14} \mathrm{C}$-palmitic acid and the lipid emulsion used in the first two experiments (group $\mathrm{C}$ ).

Blood samples were taken at intervals during the 4-hr experimental period for measurement of glycerol, triglyceride, cholesterol, glucose, free fatty acids (FFA), and insulin.

All animals were intubated with a cuffed endotracheal tube fitted with a Wright respirometer (British Oxygen Company, Harlow, England) for tidal volume determinations and were allowed to respire room air spontaneously. The expired air was collected in intermittent mandatory ventilation bags (OEM Medical, Inc., Richmond, VA) and was bubbled through $50 \mathrm{ml}$ of ethanolamine/ethylene glycol monomethyl ether/toluene (1:8:10) solution for absorption of all carbon dioxide. ${ }^{13}$ The solution was replaced hourly. A 1-ml aliquot of this solution was then added to $10 \mathrm{ml}$ of aqueous counting scintillant (Amersham, Arlington Heights, IL) and was counted for $10 \mathrm{~min}$ in a Beckman LS-230 liquid scintillation counter for determination of radioactive ${ }^{14} \mathrm{CO}_{2}$ in the expired air. In addition, one intermittent mandatory ventilation bag was analyzed every $15 \mathrm{~min}$ for expired carbon dioxide with a Beckman LB-2 Medical Gas Analyzer. Expired oxygen was measured with a S-3A Oxygen Analyzer (Applied Electrochemistry, Inc., Sunnyvale, CA). The respiratory quotient was then calculated from the $\mathrm{CO}_{2}$ produced and the $\mathrm{O}_{2}$ consumed. ${ }^{14,15}$ The rate of oxidation of ${ }^{14} \mathrm{C}$-palmitic acid was calculated from the cumulative ${ }^{14} \mathrm{CO}_{2}$ production, which was obtained by integrating the area under the curve of expired radioactive $\mathrm{CO}_{2}$. This rate was then expressed as a percentage of the initially administered dose of ${ }^{14} \mathrm{C}$-palmitic acid oxidized within $4 \mathrm{hr} .^{11}$

Triglycerides, glycerol, cholesterol, glucose, and FFA were analyzed using standard laboratory methods. Insulin was measured with a standard radioimmunoassay technique.

Statistical significance was determined using Student's $t$-test and analysis of variance with $p$ values of less than 0.05 were considered significant.

\section{RESULTS}

The mean respiratory quotient for the shock animals (group C), $0.96 \pm 0.01$, was significantly higher than that of the controls (groups A and B), $0.83 \pm 0.06$ (Fig. 1). The mean values for the actual $\mathrm{O}_{2}$ consumption and $\mathrm{CO}_{2}$ production over a 3 -hr period were $19.7 \pm 7.8$ and $16.8 \pm$ 6.3 liters for group A, $27.7 \pm 9.0$ and $22.4 \pm 8.5$ for group $B$, and $46.6 \pm 19.2$ and $44.7 \pm 11.2$ for group $C$. These data indicate that the shock puppies were clearly not hypometabolic in comparison with the other two groups. The amount of expired ${ }^{14} \mathrm{CO}$, expressed as percentage of the initially administered ${ }^{14} \mathrm{C}$-palmitic acid, was $75.7 \pm$ $30.5 \%$ in the puppies receiving only ${ }^{14} \mathrm{C}$-palmitic acid, $53.9 \pm 28.1 \%$ in the Liposyn controls, and $25.0 \pm 15.9 \%$ in the shock animals. The differences between all three groups were statistically significant (Fig. 2).

The triglyceride levels in the control dogs receiving only radioactive palmitic acid remained unchanged during the experiment. In the puppies receiving the fat

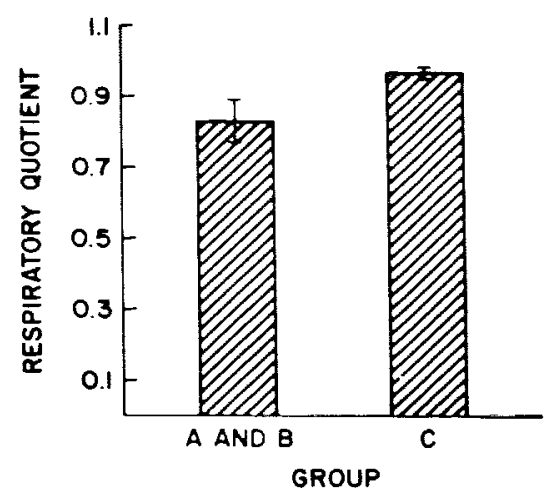

FIG. 1. Respiratory quotient.

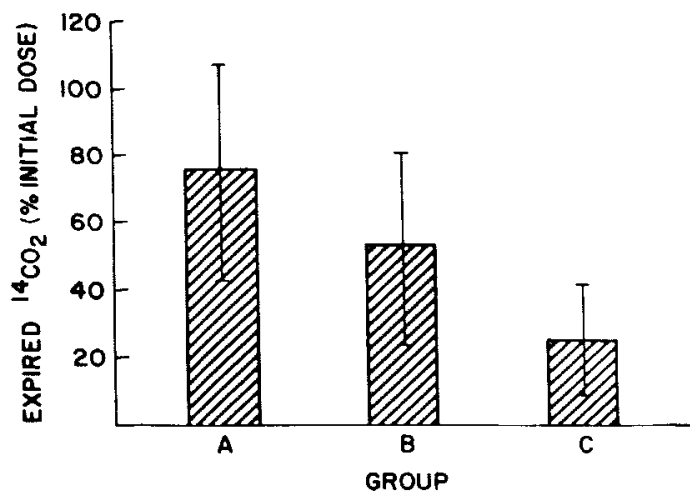

FIG. 2. Expired ${ }^{14} \mathrm{CO}_{2}$.

emulsion, the triglycerides rose to $1040 \pm 162 \mathrm{mg} / 100 \mathrm{ml}$ $2 \mathrm{~min}$ after the fat infusion and returned to baseline levels $2.5 \mathrm{hr}$ later $(83 \pm 30 \mathrm{mg} / 100 \mathrm{ml})$. In contrast, in the shock animals, triglyceride levels $2 \mathrm{~min}$ after the lipid infusion were $851 \pm 539 \mathrm{mg} / 100 \mathrm{ml}$ and remained at or above $333 \pm 213 \mathrm{mg} / 100 \mathrm{ml}$ throughout the study period. When compared with both control groups, the triglyceride levels in the shock animals at the conclusion of the experiment were significantly higher (Fig. 3).

FFA values in group $A$ remained unchanged during the first $3 \mathrm{hr}$ of the experiment. A statistically insignificant rise occurred during the last hour of the experiment. FFA levels in the Liposyn control animals rose to peak values of $1.49 \pm 1.18 \mathrm{mEq} /$ liter $30 \mathrm{~min}$ after the lipid infusion and returned to baseline $2 \mathrm{hr}$ later. The FFA levels in the shock animals remained elevated for $2.5 \mathrm{hr}$ after the lipid infusion and returned toward baseline levels only at the end of the experiment. There were no significant differences in the FFA levels in any of the three experimental groups at the conclusion of the study (Fig. 4).

Glycerol concentrations in the nonliposyn controls showed an insignificant increase to $13 \pm 20 \mathrm{mg} / 100 \mathrm{ml}$ after ${ }^{14} \mathrm{C}$-palmitic acid was administered. The remaining glycerol levels in this control group were not elevated above baseline. Glycerol levels rose to a peak value of 35 $\pm 5 \mathrm{mg} / 100 \mathrm{ml}$ at the 2 -min sampling period and remained significantly elevated for $1.5 \mathrm{hr}$ after the fat infusion in the Liposyn control animals. Glycerol values in the shock puppies increased to a peak value of $37 \pm$ 


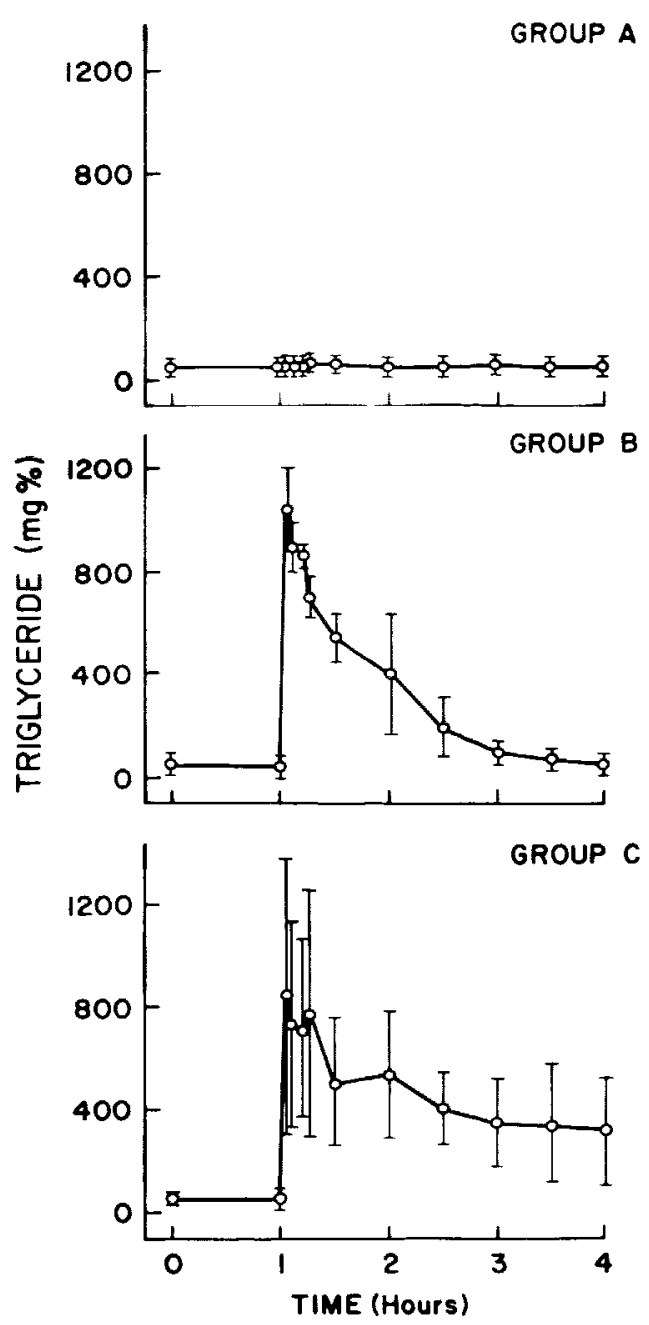

Fig. 3. Serum triglycerides.

$18 \mathrm{mg} / 100 \mathrm{ml}$ at $2 \mathrm{~min}$ and remained significantly elevated throughout the experiment. In the shock animals, glycerol levels remained significantly higher than in the Liposyn control puppies at $1.5 \mathrm{hr}$ after the lipid infusion and for the remainder of the experiment. All the glycerol levels in the shock animals were significantly higher than those seen in the non-Liposyn control group following the equilibration period (Fig. 5).

Although the shock puppies tended to have higher levels of glucose after the lipid infusion than the two control groups, these differences were not statistically significant (Table I). There were no significant changes in cholesterol (Table II).

Although there were no significant changes in plasma insulin noted in the two control groups, the value increased steadily in the shock animals after the lipid infusion to a maximum of $826 \pm 358 \mu \mathrm{U} / \mathrm{ml}$ at the end of the experimental period, which was significantly higher than the baseline value and the levels seen in the two control groups (Fig. 6).

\section{DISCUSSION}

Optimal treatment of septic shock remains controver sial, but usually includes steroid and fluid administration

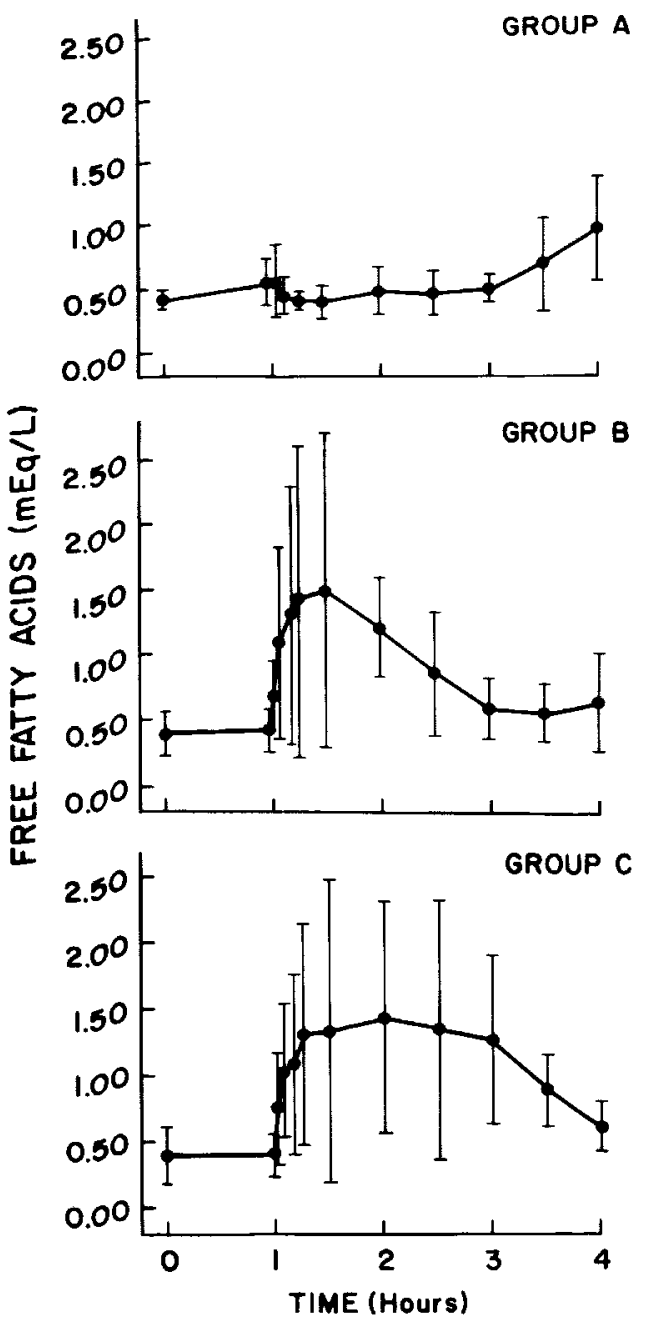

Fig. 4. Serum FFA.

to combat the severe metabolic and hemodynamic disturbances. ${ }^{16-19}$ In addition, complete nutritional support is usually required in the clinical situation. Intravenous fats are usually part of the nutritional program. The conflicting data regarding the ability of animals and humans to utilize lipid in various septic states prompted this investigation. ${ }^{1-12}$

The mean respiratory quotient of 0.96 in the shock animals compared with 0.83 for the control group indicates that glucose was the principal energy substrate being utilized by the shock puppies. The low value of ${ }^{14} \mathrm{CO}_{2}(25 \%)$ expired (vs $53.9 \%$ in the control groups) by the shock animals is further evidence that less lipid is being oxidized in the septic animals. The higher levels of triglyceride, glycerol, and FFA in the shock group indicate a reduced clearance and/or utilization of administered fat in these animals. This is in sharp contrast to the studies of Wannemacher et $\mathrm{al}^{10}$ and Nordenstrom et $\mathrm{al}^{11}$ on septic subjects not in shock and is consistent with the experience of Long et $\mathrm{al}^{12}$ in burned patients. One must use extreme caution, however, in extrapolating these data to the clinical situation because of the extreme severity of our shock model.

Both glucose and insulin levels were increased in the 

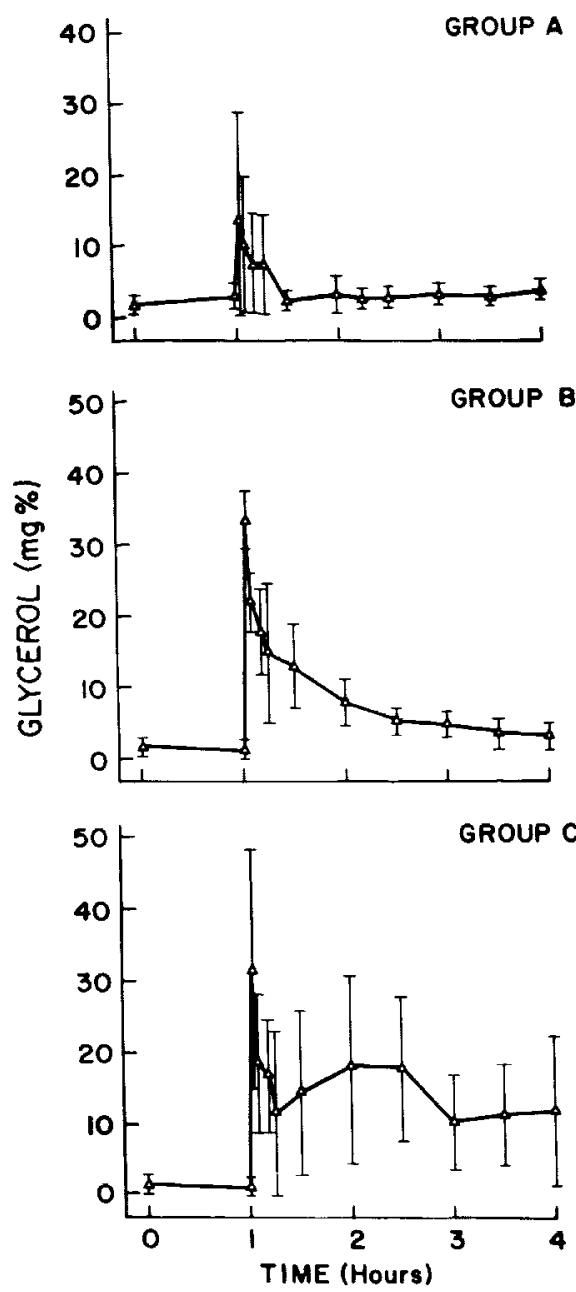

FIG. 5. Serum glycerol.

TABLE I

Blood glucose $(\mathrm{mg} / 100 \mathrm{ml})$

\begin{tabular}{ccccccccccccc}
\hline & \multicolumn{10}{c}{ Time (min) } \\
\cline { 2 - 12 } Group & 0 & 60 & 62 & 65 & 70 & 75 & $\mathbf{9 0}$ & $\mathbf{1 2 0}$ & $\mathbf{1 5 0}$ & $\mathbf{1 8 0}$ & $\mathbf{2 1 0}$ & $\mathbf{2 4 0}$ \\
\hline A & 135 & 172 & 198 & 223 & 217 & 227 & 211 & 220 & 204 & 195 & 189 & 170 \\
B & 116 & 167 & 197 & 168 & 192 & 212 & 229 & 206 & 183 & 177 & 159 & 145 \\
C & 186 & 240 & 277 & 297 & 303 & 268 & 241 & 282 & 289 & 384 & 449 & 337 \\
\hline
\end{tabular}

TABLE II

Serum cholesterol $(\mathrm{mg} / 100 \mathrm{ml})$

\begin{tabular}{ccccccccccccc}
\hline & \multicolumn{10}{c}{ Time (min) } \\
\cline { 2 - 12 } Group & $\mathbf{0}$ & $\mathbf{6 0}$ & $\mathbf{6 2}$ & $\mathbf{6 5}$ & 70 & 75 & $\mathbf{9 0}$ & 120 & 150 & 180 & 210 & $\mathbf{2 4 0}$ \\
\hline A & $\mathbf{1 8 6}$ & 227 & 194 & 218 & 199 & 231 & 268 & 242 & 235 & 253 & 240 & 232 \\
B & 282 & 201 & 228 & 248 & 234 & 218 & 226 & 281 & 281 & 266 & 241 & 255 \\
C & 232 & 202 & 283 & 267 & 262 & 260 & 263 & 269 & 270 & 234 & 209 & 220 \\
\hline
\end{tabular}

shock puppies; however, the increase in insulin to 826 $\mu \mathrm{U} / \mathrm{ml}$ at the conclusion of the experiment was dramatic. Munro $^{20}$ and Beisel ${ }^{21}$ have observed similar increases in both glucose and insulin in patients with sepsis and fever and have suggested that the high insulin levels inhibit flow of FFA from adipose tissue, and thereby reverse the ketosis.
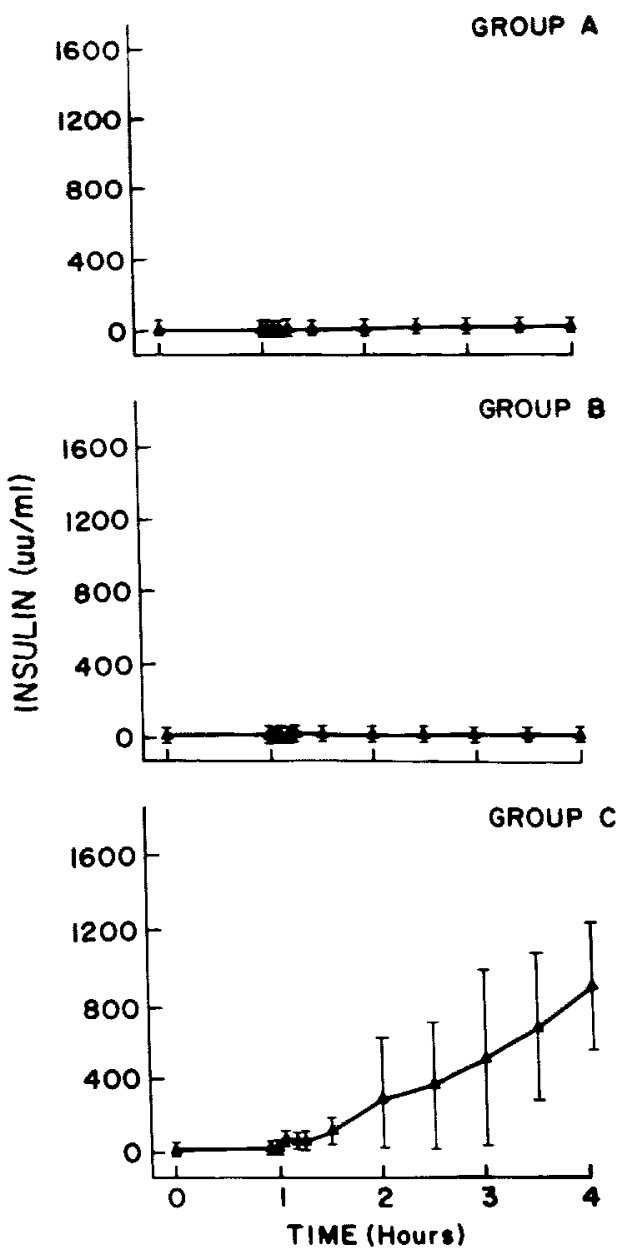

Fig. 6. Serum insulin.

It is possible that the $E$. coli bacteria themselves inhibited the activity of lipoprotein lipase, the principal enzyme involved in the hydrolysis of triglycerides, as reported by Lanza-Jacoby et $\mathrm{al}^{2}$ in rats. This would obviously result in decreased lipid clearance and elevated levels of serum triglycerides.

The high levels of triglyceride, FFA, and glycerol could also be attributed to the decreased peripheral perfusion seen in this severe septic shock model. The decreased liver blood flow could account for a lowered clearance of lipids with the resultant elevated levels of triglyceride, FFA, and glycerol. In addition, the increased catecholamine response to the $E$. coli shock probably contributed to the elevated lipid levels. ${ }^{6.22}$ However, these two factors would not account for the lowered rate of ${ }^{14} \mathrm{CO}_{2}$ production or the high respiratory quotients observed in the septic puppies. Therefore, our data strongly suggest that the septic animals in this study are unable to metabolize and oxidize an exogenous source of neutral fats as well as the control puppies and that they preferentially burn carbohydrate during septic shock.

\section{REFERENCES}

1. Horwitz DL: Effects of endotoxin and E. coli shock on the metabolism of lipids and carbohydrate. Adv Exp Biol Med 23:195-202, 
1971

2. Lanza-Jacoby S. Lansey SC. Cleary MP. et al: Alterations in lipogenic enzymes and lipoprotein lipase activity during gramnegative sepsis in the rat. Arch Surg 117:144-147, 1982

3. Fiser RH. Denniston JC. Beisel WR: Endotoxemia in the Rhesus monkey: Alterations in host lipid and carbohydrate metabolism. Pediatr Res 8:13-17, 1974

4. Cook JA, Wise WC, Callihan CS: Resistance of essential fatty acid-deficient rats to endotoxic shock. Circ Shock 6:333-342, 1979

5. Gallin JI, Kaye D. O'Leary WM: Serum lipids in infection. N Engl J Med 281:1081-1086, 1969

6. Griffiths J, Groves AC, Leung FYT: The relationship of plasma catecholamines to serum triglycerides in canine gram-negative bacteremia. Surg Gynecol Obstet 134:795-798, 1972

7. Fiser RH, Denniston JC, Beisel WR: Infection with Diplococcus pneumoniae and Salmonella typhimurium in monkeys: changes in plasma lipids and lipoproteins. J Infect Dis 125:54-60, 1972

8. Hirsch RL, McKay DG, Travers RI, et al: Hyperlipidemia, fatty liver, and bromosulfophthalein retention in rabbits injected intravenously with bacterial endotoxins. J Lipid Res 5:563-568, 1964

9. Kaufmann RL, Matson CF, Rowberg AH, et al: Defective lipid disposal mechanisms during bacterial infection in Rhesus monkeys. Metabolism 25:615-624, 1976

10. Wannemacher RW Jr, Kaminski MV, Dinterman RE, et al: Use of lipid calories during pneumococcal sepsis in the Rhesus monkey. JPEN 6:100-105, 1982

11. Nordenstrom J, Carpentier YA, Askanazi J, et al: Metabolic utilization of intravenous fat emulsion during total parenteral nutrition. Ann Surg 196:221-231, 1982

12. Long JM III, Wilmore DW, Mason AD Jr, et al: Effect of carbo- hydrate and fats intake on nitrogen excretion during total intravenous feeding. Ann Surg 185:417-422, 1977

13. Jeffay $\mathrm{H}$, Alvarez J: Liquid scintillation counting of C-14. Anal Chem 33:612-615, 1961

14. Brobeck JR: Energy exchange. IN Medical Physiology, Mountcastle VB (eds). The C.V. Mosby Company, St. Louis, MO, 1980, pp $1239-1245$

15. Martin MJ, Horwitz DL, Nattrass M, et al: Effects of mild hyperinsulinemia on the metabolic response to exercise. Metabolism 30:668-694, 1981

16. Benner JW, Polley TZ, Strodel WE, et al: Fluid resuscitation in live Escherichia coli septic shock in puppies. J Pediatr Surg 15:527530,1980

17. Connors RH, Coran AG, Drongowski RA, et al: Corticosteroid therapy in hemorrhagic and septic shock in puppies. J Pediatr Surg 15:790-796, 1980

18. Connors RH, Coran AG, Drongowski RA, et al: Combined fluid and corticosteroid therapy in septic shock in puppies. World J Surg $7: 661-668,1983$

19. Hinshaw LB, Archer LT, Beller-Todd BK, et al: Survival of primates in $\mathrm{LD}_{100}$ septic shock following steroid/antibiotic therapy. J Surg Res 28:151-170, 1980

20. Munro AN: Metabolic integration of organs in health and disease. JPEN 6:271-279, 1982

21. Beisel WR: Impact of infectious disease upon fat metabolism and immune functions. Cancer Res 41:3797-3798, 1981

22. Allen DJ, Hillman CC, Ashmore J: Studies on a biphasic lipolytic response to catecholamines in isolated fat cells. Biochem Pharmacol 18:2233-2240, 1969 